\title{
BMJ Open Neurodevelopmental outcomes at 7 years' corrected age in preterm infants who were fed high-dose docosahexaenoic acid to term equivalent: a follow-up of a randomised controlled trial
}

Carmel T Collins, ${ }^{1,2,3,4}$ Robert A Gibson, ${ }^{1,2,4}$ Peter J Anderson, ${ }^{5,6}$ Andrew J McPhee, ${ }^{2,3,7}$ Thomas R Sullivan, ${ }^{8}$ Jacqueline F Gould, ${ }^{1,4}$ Philip Ryan, ${ }^{8}$ Lex W Doyle, ${ }^{5,6,9}$ Peter G Davis, ${ }^{5,9}$ Judy E McMichael, ${ }^{10,11}$ Noel P French, ${ }^{10,11}$ Paul B Colditz, ${ }^{12}$ Karen Simmer, ${ }^{10,11}$ Scott A Morris, ${ }^{13}$ Maria Makrides ${ }^{1,2,3,4}$

To cite: Collins CT, Gibson RA, Anderson PJ, et al. Neurodevelopmental outcomes at 7 years' corrected age in preterm infants who were fed high-dose docosahexaenoic acid to term equivalent: a follow-up of a randomised controlled trial. BMJ Open 2015;5:e007314. doi:10.1136/bmjopen-2014007314

- Prepublication history and additional material is available. To view please visit the journal (http://dx.doi.org/ 10.1136/bmjopen-2014007314).

Received 27 November 2014 Revised 21 February 2015 Accepted 24 February 2015

\section{CrossMark}

For numbered affiliations see end of article.

Correspondence to Professor Maria Makrides; maria.makrides@health.sa. gov.au

\section{ABSTRACT}

Objective: To determine if improvements in cognitive outcome detected at 18 months' corrected age (CA) in infants born $<33$ weeks' gestation receiving a highdocosahexaenoic acid (DHA) compared with standardDHA diet were sustained in early childhood.

Design: Follow-up of a multicentre randomised controlled trial. Randomisation was stratified for sex, birth weight ( $<1250 \mathrm{vs} \geq 1250 \mathrm{~g})$ and hospital.

Setting: Five Australian tertiary hospitals from 2008 to 2013.

Participants: 626 of the 657 participants randomised between 2001 and 2005 were eligible to participate.

Interventions: High-DHA ( $\approx 1 \%$ total fatty acids) enteral feeds compared with standard-DHA $(\approx 0.3 \%$ total fatty acids) from age 2-4 days until term CA.

Primary outcome: Full Scale IQ of the Wechsler Abbreviated Scale of Intelligence (WASI) at 7 years CA. Prespecified subgroup analyses based on the randomisation strata (sex, birth weight) were conducted. Results: 604 (92\% of the 657 originally randomised) consented to participate (291 high-DHA, 313 standardDHA). To address missing data in the 604 consenting participants (22 for primary outcome), multiple imputation was performed. The Full Scale IQ was not significantly different between groups (high-DHA 98.3, SD 14.0, standard-DHA 98.5, SD 14.9; mean difference adjusted for sex, birthweight strata and hospital -0.3 , $95 \% \mathrm{Cl}-2.9$ to $2.2 ; \mathrm{p}=0.79$ ). There were no significant differences in any secondary outcomes. In prespecified subgroup analyses, there was a significant sex by treatment interaction on measures of parent-reported executive function and behaviour. Scores were within the normal range but girls receiving the high-DHA diet scored significantly higher (poorer outcome) compared with girls receiving the standard-DHA diet.

Conclusions: Supplementing the diets of preterm infants with a DHA dose of approximately $1 \%$ total fatty acids from days 2-4 until term CA showed no evidence of benefit at 7 years' $C A$.

\section{Strengths and limitations of this study}

First study to evaluate the effect a diet that provides the estimated in utero accretion rate of docosahexaenoic acid in infancy has on neurodevelopmental outcomes in early childhood.

- Sample size large enough to detect a four-point difference in Full Scale IQ if it existed.

- Low risk of bias achieved through minimal attrition rate $(92 \%$ of children originally randomised consented to participate) and blinding of research personnel, outcome assessors and all but 12 families.

- Robust objective assessments of neurodevelopmental outcomes undertaken by psychologists after extensive training and ongoing auditing.

- A limitation of the study was not including a teacher assessment of the child's behaviour.

Trial registration number: Australian New Zealand Clinical Trials Registry: ACTRN12606000327583.

\section{INTRODUCTION}

With advances in clinical care, increasing numbers of very preterm infants are surviving into childhood. However, neurobehavioural impairments have not decreased, imposing an increasing burden on health and education systems. There remains an inverse relationship between cognitive functioning and gestational age, with the most preterm survivors being most affected by poor cognitive functioning. ${ }^{1}$

The long chain polyunsaturated fatty acid docosahexaenoic acid (DHA; 22:6 n-3) is a 
major lipid in the brain and is known to be involved in neurogenesis and neurite growth. ${ }^{2}$ Infants born very preterm are deprived of the placental supply of DHA that occurs in the last trimester of pregnancy and have lower brain concentrations of DHA than term-born infants, ${ }^{3}$ possibly contributing to their high risk of developmental delay. The only trials where the dose of DHA has matched the estimated in utero accretion rate of DHA $(\approx 45 \mathrm{mg} / \mathrm{kg} / \text { day })^{4}$ and was inclusive of breast milk feeding have shown some short-term benefit of DHA supplementation. ${ }^{5-7}$ The DHA for the Improvement of Neurodevelopmental Outcome in preterm infants (DINO) trial is the largest published trial of DHA supplementation in very preterm infants. ${ }^{6}$ The DINO trial showed that although mean cognitive development at 18 months' corrected age (CA) was not altered overall, the proportion of infants with severe developmental delay was significantly reduced. In prespecified subgroup analyses, the greatest effect was seen in girls and there was a strong suggestion of benefit in the smallest infants. ${ }^{6}$

Assessing neurodevelopment within the first 2 years of life remains a cornerstone of preterm infant follow-up ensuring early detection of problems and initiation of appropriate support services. However, developmental outcomes measured in the first 2 years may not accurately predict a longer term developmental outcome. ${ }^{8} 9$ Related to this, some cognitive domains that are hypothesised to be influenced by DHA, such as executive function and memory, are difficult to reliably assess in early childhood. We therefore aimed to determine the effect of DHA given up to term equivalent to infants born less than 33 weeks' gestation, on neurodevelopment at 7 years' CA.

\section{METHODS}

This is a follow-up at 7-years' CA of infants who participated in the DINO randomised controlled trial.

\section{Initial study-the DINO trial}

The DINO trial methods have been previously published. ${ }^{6}$ Between 2001 and 2005, 657 infants born $<33$ weeks' gestation from five Australian tertiary hospitals were randomised, from within 5 days of their first enteral feed, to receive a high-DHA or standard-DHA diet until 40 weeks' CA. Infants were excluded if they had a major congenital or chromosomal abnormality, were from a multiple birth in which not all live-born infants were eligible, were in other trials of fatty acid supplementation, or if fish oil was contraindicated in the lactating mother. Mother-infant pairs were randomly assigned a unique study number using a computer-driven telephone randomisation service according to an independently generated randomisation schedule. Stratification was by centre, birth weight $(<1250$ and $\geq 1250 \mathrm{~g})$ and infant sex. Multiple births were considered a single randomisation unit. Participants were enrolled and assigned to their study group by research nurses at each centre.

\section{Dietary treatments}

Lactating women with infants randomised to the high-DHA group took DHA-rich tuna oil capsules daily to achieve a breast milk DHA concentration $\approx 1 \%$ of total fatty acids without altering the naturally occurring concentration of arachidonic acid. Infants requiring formula received a high-DHA preterm formula $(\approx 1.0 \%$ DHA and $\approx 0.6 \%$ AA). The high-DHA diet provided $\approx 50 \mathrm{mg} / \mathrm{kg} /$ day of DHA. Lactating women with infants randomised to standard-DHA took placebo soy oil capsules. Infants requiring formula received standard preterm infant formula $(\approx 0.35 \% \mathrm{DHA})$. The standard-DHA diet provided $\approx 20 \mathrm{mg} / \mathrm{kg} /$ day of DHA. Postdischarge, women who were breast feeding were encouraged to continue, and those using formula were encouraged to use a commercially available term formula supplemented with DHA. Parents, clinicians and all research personnel were blinded to the participant study group.

\section{Present study-follow-up at 7 years' CA}

The parent or guardian of each participant provided written informed consent. A letter of invitation was sent to caregivers of eligible children followed by a telephone call. Of the 657 infants randomised to the DINO trial, 626 children were eligible to participate in the 7-year CA follow-up (ie, had not withdrawn from the study or died). Clinicians and researchers remained unaware of group allocations; the statistician was unblinded during the 18-month CA analysis of the DINO results. Twelve families (6 children in each group) requested to be unblinded after publication of the 18-month CA results. Assessments were administered by trained psychologists blinded to group allocation and the 18-month CA assessment results. Assessments were conducted at the participating perinatal centre; if this was unsuitable for the family, assessments were conducted elsewhere. The assessment, including short breaks, took $3 \mathrm{~h}$ and was conducted within \pm 3 months of the 7-year CA date. In difficult to locate families, efforts to conduct an assessment continued beyond this age. The child's CA (chronological age reduced by the number of weeks born before 40 weeks of gestation) was used to calculate age-standardised test scores, thus avoiding a known bias in cognitive scores which we have reported to be clinically important at all ages through childhood. ${ }^{10}$

\section{Primary outcome}

The primary outcome was general intellectual ability as assessed by the Full Scale IQ of the Wechsler Abbreviated Scale of Intelligence (WASI). The WASI consists of four subtests (Vocabulary, Similarities, Block Design and Matrix Reasoning) and provides a brief and reliable estimate of the child's intellectual functioning. These four subtests yield the Full Scale IQ which is age standardised with a mean of 100 (SD 15). In the event that children had a recent Full Scale IQ assessment using a different psychological test, the results from that test were used. 


\section{Secondary outcomes}

Secondary outcomes included cognitive domains that have been previously demonstrated to be areas of concern for preterm children, as well as those domains thought to be sensitive to DHA depletion and included intellectual impairment, Verbal and Performance IQ attention, memory and learning, executive functioning, behaviour, visual-spatial perceptual skills, educational progress and quality of life. Intellectual impairment, assessed using the WASI Full Scale IQ was defined as mild $(\mathrm{IQ}<85)$ and major (IQ $<70$ ). Verbal and performance IQ scores were acquired from the WASI. Subtests of the Test of Everyday Attention for Children measured selective attention (Sky Search), sustained attention (Score!), shifting attention/ attentional control (Creature Counting) and divided attention (Sky Search Dual Task). ${ }^{11}$ The score for Divided Attention was calculated by multiplying the proportion of visual stimuli found by the proportion of auditory stimuli counted, multiplied by 10 (with 10 signifying a perfect score). ${ }^{12}$ Aspects of executive functioning were assessed with the Rey Complex Figure, the Fruit Stroop Test and the parent-completed Behaviour Rating Inventory of Executive Functioning (BRIEF).

Short-term verbal memory and learning were assessed with the Rey Auditory Verbal Learning Test. Visual Perception was assessed with the Visual-Spatial Relations, Visual Figure-Ground and Visual Closure subtests of the Test of Visual Perceptual Skills, third edition. Educational progress was assessed with the Word Reading, Spelling, and Math Computation subtests of the Wide Range Achievement Test fourth edition. Parents were also questioned on whether their child had repeated a year at school.

Child behaviour was assessed with two parent-completed questionnaires; the Conners 3rd Edition ADHD Index (Conners 3 AI-parent) which screens for Attention Deficit Hyperactivity Disorder (ADHD), and the Strengths and Difficulties Questionnaire which screens for emotional and behaviour problems. General health status and health-related quality of life were measured using parentcompleted questionnaires: the Multi-attributed Health Status Classification System-Health Utilities Index Mark 3 and the Pediatric Quality of Life Inventory.

Information on family functioning (Family Assessment Device), and recent family events (Recent Life Events Questionnaire) were collected through parent-completed questionnaires. General child health, home environment, DHA containing diet and supplement use were collected.

If the child was unable to complete an assessment due to severe developmental delay, they were assigned the lowest possible score. Outcome scores were recorded as missing if the child was uncooperative or they were untestable due to a motor or sensory impairment.

\section{SAMPLE SIZE AND STATISTICAL ANALYSIS}

This follow-up study was designed in 2007 before the 18-month CA assessments had been completed. We anticipated a follow-up rate of at least $90 \%$ at 7 years, that is, $>590$ children (295 per group). Using blinded 18-month Mental Development Index results available at the time, we estimated that the design effect due to the non-independence of multiple births was 1.14 (intraclass correlation coefficient (ICC) $=0.70$, average of 1.20 infants per mother), giving an effective sample size of 259 children per group at 7 years. With these assumptions, we had $85 \%$ power $(\alpha=0.05)$ to detect a four-point minimum difference in the Full Scale IQ scores (SD 15) between groups. In prespecified subgroup analyses by randomisation strata (sex and birth weight $<1250 \mathrm{~g}$ ), we had $85 \%$ power $(\alpha=0.05)$ to detect a six-point difference (SD 15).

\section{Data management and analysis}

All participants who consented to participate in the 7-year CA follow-up (whether they completed the assessments or not) were analysed according to the group to which they were allocated. To address missing outcome data, multiple imputation was performed separately by treatment group using chained equations ${ }^{13}$ to create 100 complete data sets, under the assumption that data were missing at random. Imputation models included covariates prespecified for adjustment and auxiliary variables that helped to satisfy the missing at random assumption or that were predictive of outcomes. Following analysis, the effect estimates from the imputed data sets were combined using Rubin's rules. ${ }^{14}$ The primary analysis was based on imputed data and included all participants who consented to the follow-up study. Sensitivity analyses were performed on the available data and on imputed data for the 657 children in the original sample, excluding deaths. All analyses produced similar results and only the results of the primary analysis are presented.

Outcomes were analysed using generalised estimating equations (GEE) to account for clustering due to multiple births. Normally distributed outcomes were analysed using a linear GEE, with the effect of treatment expressed as a mean difference with $95 \%$ CI. Binary outcomes were analysed using log-binomial GEE, with the effect of treatment expressed as a relative risk (RR) with 95\% CI. Unadjusted and adjusted analyses were performed, with adjustment for the stratification variables (centre, birth weight, sex). Statistical significance was assessed at the two-sided $\mathrm{p}<0.05$ level. All analyses followed a prespecified statistical analysis plan and were performed using SAS V.9.3 (Cary, North Carolina, USA) and Stata Release V.12 (Statacorp LP, College Station, Texas, USA).

\section{RESULTS}

\section{Study participants}

The participant flow for infants randomly assigned to receive the high-DHA or standard-DHA diet and assessed at 7 years' CA is shown in the figure 1 . Follow-up assessments began in June 2008 and ended on 10 July 2013. In total, 604 families consented to participate in the 7-year 

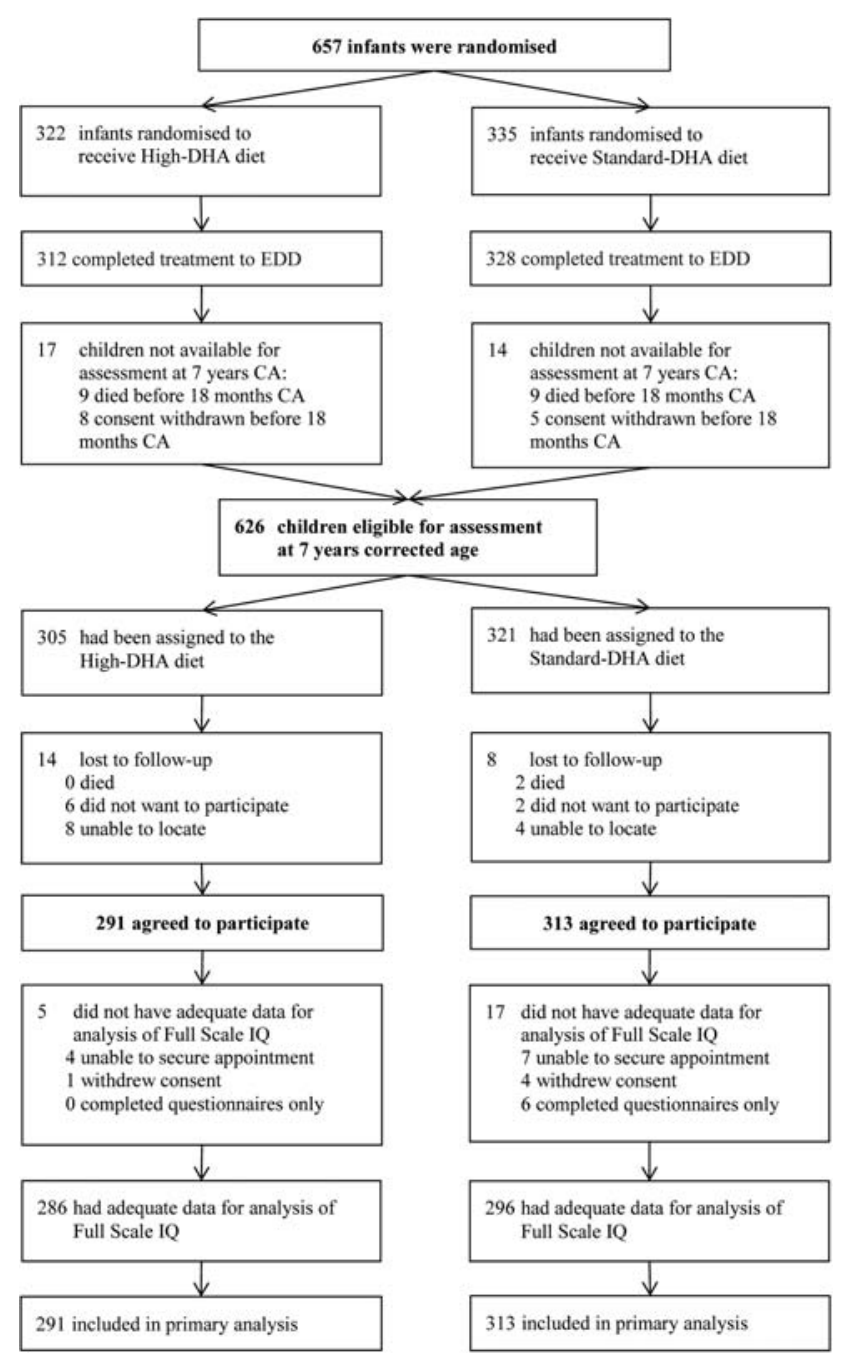

Figure 1 DINO trial participant flow in the 7-year follow-up. $\mathrm{CA}$, corrected age; DHA, docosahexaenoic acid; DINO, Docosahexaenoic acid for the Improvement of Neurodevelopmental Outcome in preterm infants; EDD, expected date of delivery. follow-up (92\% of the 657 originally randomised). Adequate data for analysis of the primary outcome (Full Scale IQ) were available for $582(89 \%)$ of the 657 randomised children and $93 \%$ of the 626 children eligible for the 7-year follow-up (high-DHA $\mathrm{n}=286$, standard-DHA $\mathrm{n}=296$; figure 1 ). Twenty children (high-DHA $\mathrm{n}=8$, standard-DHA $\mathrm{n}=12$ ) were assessed using a different IQ measure (Wechsler Preschool and Primary Scale of Intelligence $\mathrm{n}=17$; Wechsler Intelligence Scale for Children $n=2$; or Differential Ability Scales $n=1$ ) because of their involvement in other studies.

The characteristics of the 604 children consenting to follow-up were similar at randomisation (table 1). Two children (both in the standard-DHA group) died between 18 months' and 7 years' CA (table 2); their deaths were reviewed by an independent Mortality Review Committee blinded to treatment group and deemed to be unrelated to the study product or protocol. Children were assessed at a mean of 7.2 years' CA (table 2). Family functioning and life events affecting the children were similar between groups based on scores from the Family Assessment Device and Recent Life Events (table 2). English was the primary language spoken at home for the majority of children and the consumption of DHA containing foods or supplements was similar between groups (table 2 ).

\section{Primary outcome at 7 years' $C A$}

The Full Scale IQ was not significantly different between the two groups (high-DHA 98.3, SD 14.0, standard-DHA 98.5, SD 14.9; mean difference adjusted for sex, birth weight $(<1250$ or $\geq 1250 \mathrm{~g})$ and the recruiting centre $-0.3,95 \% \mathrm{CI}-2.9$ to $2.2 ; \mathrm{p}=0.79$ ) (table 3 ).

\section{Secondary outcomes at 7 years' $\mathrm{CA}$}

Intellectual impairment, that is, a Full Scale IQ $<85$ or $<70$ did not differ significantly between the groups (table 3 ),

Table 1 Baseline (at randomisation) clinical and demographic characteristics

\begin{tabular}{|c|c|c|}
\hline & $\begin{array}{l}\text { High-DHA } \\
\text { diet }(n=291)\end{array}$ & $\begin{array}{l}\text { Standard-DHA } \\
\text { diet }(n=313)\end{array}$ \\
\hline Median (IQR) gestational age (weeks) & $30.0(28.0-31.0)$ & $30.0(28.0-31.0)$ \\
\hline Mean (SD) birth weight (g) & $1307(420)$ & $1320(410)$ \\
\hline Male sex & $152(52.2)$ & $172(55.0)$ \\
\hline Singleton birth & $208(71.5)$ & $195(62.3)$ \\
\hline Birth weight $<1250 \mathrm{~g}$ & $132(45.4)$ & $139(44.4)$ \\
\hline Birth weight $<10$ th centile* & $54(18.6)$ & $57(18.2)$ \\
\hline Mean (SD) birth length $(\mathrm{cm})(\mathrm{n}=222 / 238) \dagger$ & $38.2(3.9)$ & $38.2(4.1)$ \\
\hline Mean (SD) birth head circumference $(\mathrm{cm})(n=248 / 261) \dagger$ & $27.2(2.8)$ & $27.4(2.7)$ \\
\hline Mean (SD) maternal age (years) & $29.9(5.7)$ & $30.5(5.2)$ \\
\hline Mother smoked during pregnancy & $77(26.5)$ & $76(24.3)$ \\
\hline Infant received breast milk at trial entry & $271(93.1)$ & $291(93.0)$ \\
\hline Mother completed secondary education $(n=280 / 293) \dagger$ & $175(62.5)$ & $172(58.7)$ \\
\hline Father completed secondary education $(n=270 / 280) \dagger$ & $146(54.1)$ & $155(55.4)$ \\
\hline
\end{tabular}


Table 2 Postrandomisation treatment group comparison of demographic, social and clinical characteristics

\begin{tabular}{|c|c|c|c|}
\hline & $\begin{array}{l}\text { High-DHA } \\
\text { diet }(n=291)\end{array}$ & $\begin{array}{l}\text { Standard-DHA } \\
\text { diet }(n=313)\end{array}$ & p Value \\
\hline \multicolumn{4}{|l|}{ Social variables } \\
\hline Death between 18 months and 7 years' corrected age $\left(n=313 / 326^{\star}\right)$ & $0(0.0)$ & $2(0.6)$ & $0.50 \dagger$ \\
\hline Family unblinded before the 7-year corrected age assessment & $6(2.1)$ & $6(1.9)$ & $>0.99$ \\
\hline English primary language spoken at home $(n=285 / 298)$ & $278(97.5)$ & $296(99.3)$ & 0.10 \\
\hline Mean (SD) Recent Life Events, total events still impacting ( $n=278 / 290)$ & $0.5(1.2)$ & $0.4(1.0)$ & 0.47 \\
\hline Mean (SD) Family Assessment Device general functioning score $(n=278 / 289)$ & $1.6(0.4)$ & $1.5(0.4)$ & 0.24 \\
\hline \multicolumn{4}{|l|}{ Dietary variables } \\
\hline Had fish in the last month $(n=285 / 298)$ & $248(87.0)$ & $267(89.6)$ & 0.39 \\
\hline Mean (SD) number of fish meals in the last month $(n=246 / 266)$ & $5.0(3.8)$ & $5.1(3.6)$ & 0.96 \\
\hline
\end{tabular}

and nor did the Verbal and Performance IQ scores (table 3). There was no effect of the high-DHA diet on selective, sustained, shifting or divided attention, shortterm verbal memory or learning ability, executive functioning, visual perception or academic achievement (table 4).

According to parental reports, there were no differences between the high-DHA and standard-DHA groups in executive functioning, ADHD symptoms, emotional and behaviour problems, general health status, health-related quality of life or in the percentage of children repeating a school year (table 5). The parent-reported health-related quality of life neared 'perfect health' (score of 1) for both groups. Furthermore, parental reports of a diagnosis of ADHD
(high-DHA 9/285, 3.2\%; standard-DHA 7/298, 2.3\%; $\mathrm{RR}=1.34,95 \%$ CI 0.51 to $3.56 ; \mathrm{p}=0.55)$, $\mathrm{ADHD}$ and using medication (high-DHA 6/285, 2.1\%; standard-DHA 4/ 298, $1.3 \%$; RR=1.57, $95 \%$ CI 0.45 to $5.50 ; \mathrm{p}=0.48$ ) autism spectrum disorder (high-DHA 10/285, $3.5 \%$; standard-DHA 9/298, 3.0\%; RR=1.16, 95\% CI 0.48 to 2.82; $\mathrm{p}=0.74$ ) or cerebral palsy (high-DHA 14/285, 4.9\%; standard-DHA $9 / 298,3.0 \%$; $R=1.63,95 \%$ CI 0.72 to $3.70 ; \mathrm{p}=0.25$ ) did not differ significantly between groups.

\section{Subgroup analysis by randomisation strata-sex}

There was no interaction effect between dietary treatment and sex for the primary outcome Full Scale IQ (see web appendix A).

Table 3 Primary and secondary outcomes from the Wechsler Abbreviated Scale of Intelligence* at 7 years' corrected age

\begin{tabular}{|c|c|c|c|c|c|c|}
\hline Outcome & $\begin{array}{l}\text { High-DHA } \\
\text { diet mean } \\
\text { (SD) } \mathrm{N}=291\end{array}$ & $\begin{array}{l}\text { Standard-DHA } \\
\text { diet mean (SD) } \\
\mathrm{N}=313\end{array}$ & $\begin{array}{l}\text { Unadjusted } \\
\text { treatment effect } \\
(95 \% \mathrm{Cl})\end{array}$ & $\begin{array}{l}\text { Unadjusted } \\
\text { p Value }\end{array}$ & $\begin{array}{l}\text { Adjusted } \\
\text { treatment effect } \\
(95 \% \mathrm{Cl}) \dagger\end{array}$ & $\begin{array}{l}\text { Adjusted } \\
\text { p Value }\end{array}$ \\
\hline \multicolumn{7}{|l|}{ Primary } \\
\hline Full Scale IQ & $98.3(14.0)$ & $98.5(14.9)$ & $-0.3(-2.9$ to 2.4$)$ & 0.85 & $-0.3(-2.9$ to 2.2$)$ & 0.79 \\
\hline \multicolumn{7}{|l|}{ Secondary } \\
\hline Verbal IQ & $98.0(14.2)$ & $98.8(15.8)$ & $-0.7(-3.5$ to 2.0$)$ & 0.59 & $-0.9(-3.5$ to 1.8$)$ & 0.52 \\
\hline Performance IQ & $98.5(14.5)$ & $98.5(13.6)$ & $0.0(-2.5$ to 2.6$)$ & 0.98 & $-0.0(-2.5$ to 2.5$)$ & 0.99 \\
\hline $\begin{array}{l}\text { Number (\%) Full Scale } \\
I Q<85 \ddagger\end{array}$ & $40(13.6)$ & $44(14.1)$ & $1.0(0.6$ to 1.5$)$ & 0.87 & $1.0(0.6$ to 1.5$)$ & 0.84 \\
\hline $\begin{array}{l}\text { Number (\%) Full Scale } \\
I Q<70 \S(n=286 / 296)\end{array}$ & $3(1.0)$ & $5(1.7)$ & & 0.73 & & \\
\hline \multicolumn{7}{|c|}{$\begin{array}{l}\text { Values are mean (SD) and treatment effects are mean difference based on imputed data unless otherwise indicated. } \\
\text { *Wechsler Abbreviated Scale of Intelligence IQ, the mean (SD) score is } 100(15) \text {, range } 50-160 . \\
\text { †Adjusted for sex, birth weight }(<1250 \text { or } \geq 1250 \mathrm{~g}) \text { and recruiting centre. } \\
\text { †Treatment effect is relative risk. } \\
\text { §Raw data used due to the small number of cases; compared using the Fisher exact test. } \\
\text { DHA, docosahexaenoic acid. }\end{array}$} \\
\hline
\end{tabular}




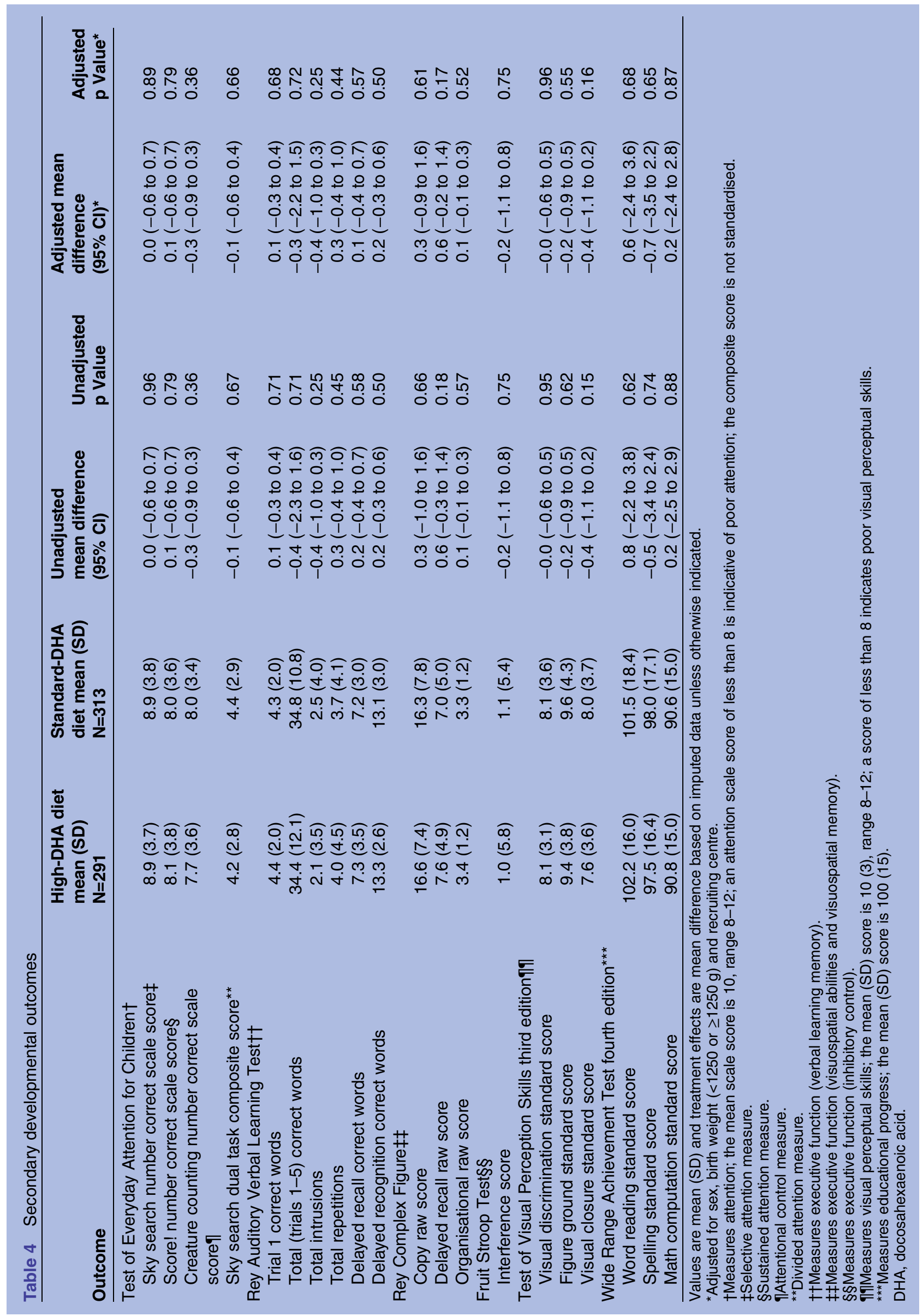




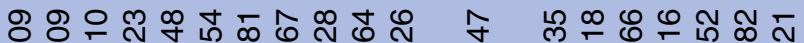
00000000000 0 0.000000

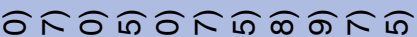
ษ 오옹ㅇㅇㅇㅇㅇㅇㅇㅇㅇㅇㅇㅇㅇㅇㅇ

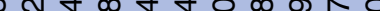

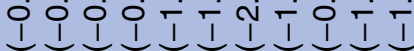
बर

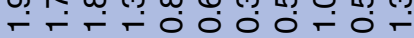

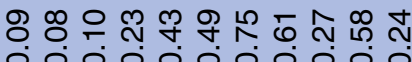

ঙ̊

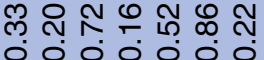

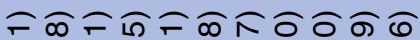
षं்

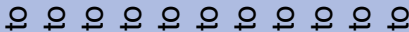

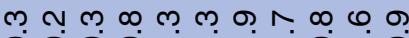
IIITITITOII

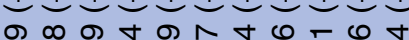
の
ลิ

$+2$

I T.
เกิ 000000. 으 오 으오 오 오 우 $N-m-N m+$ $\begin{array}{lllllll}1 & 1 & 1 & 1 & 1 & 1 & 1 \\ 0 & 0 & 0 & 0 & 0 & 1\end{array}$ N NTNTON 0000000

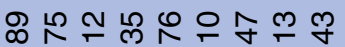
०० 0000000

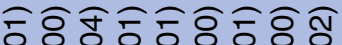
$\circ 00000000$ 으응ㅇㅇㅇㅇㅇㅇㅇㅇㅇㅇㅇㅇㅡ

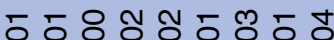

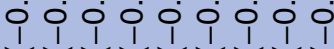
88 ㅇํㄷㅇㄷㄷㄷำ o o o i i i o i i
ำำำ $\circ 00000$

ঔすのす๙す ก 오 응ㅇㅇㅇ 오 우 L $00-10$ 00 1 0 \% 1111 เ $\infty$ m $\infty \circ$

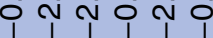

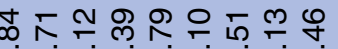
000000000

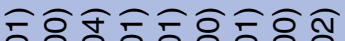

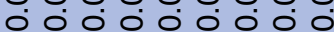
오 오으오 오 오오 오오 ธธธ 8 ิํㅇํำ $\begin{array}{lllll}1 & 1 & 1 & 1 & 1 \\ 0 & 1 & 1 & 1 & 1\end{array}$ 88 등ํㄷㄷㄷำ o io i o í i ó

농ํㅇำำำำ ० 000000

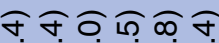
กั่ no n 오 우 오오오우 $\forall 0.0 \%$ ल 0 1 1 1 (1)

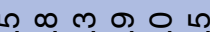
i

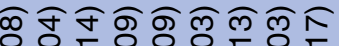

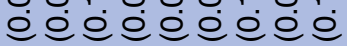
용요용요

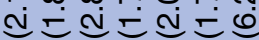
लक लि-क -

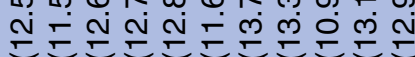

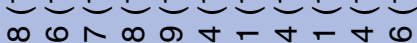

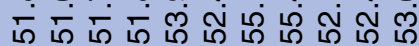

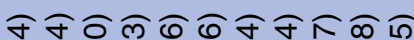

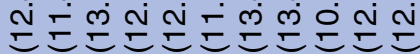
ก 6 N ถึ่

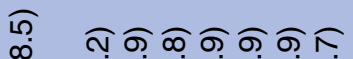

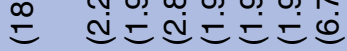
o $\forall-\forall \infty N a \infty$

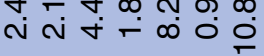

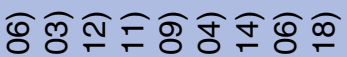

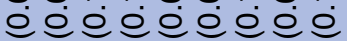

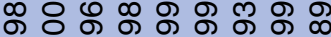
$0 \div 0000000$
อิธล์คด

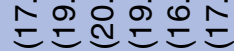

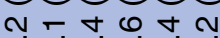
命定市占命

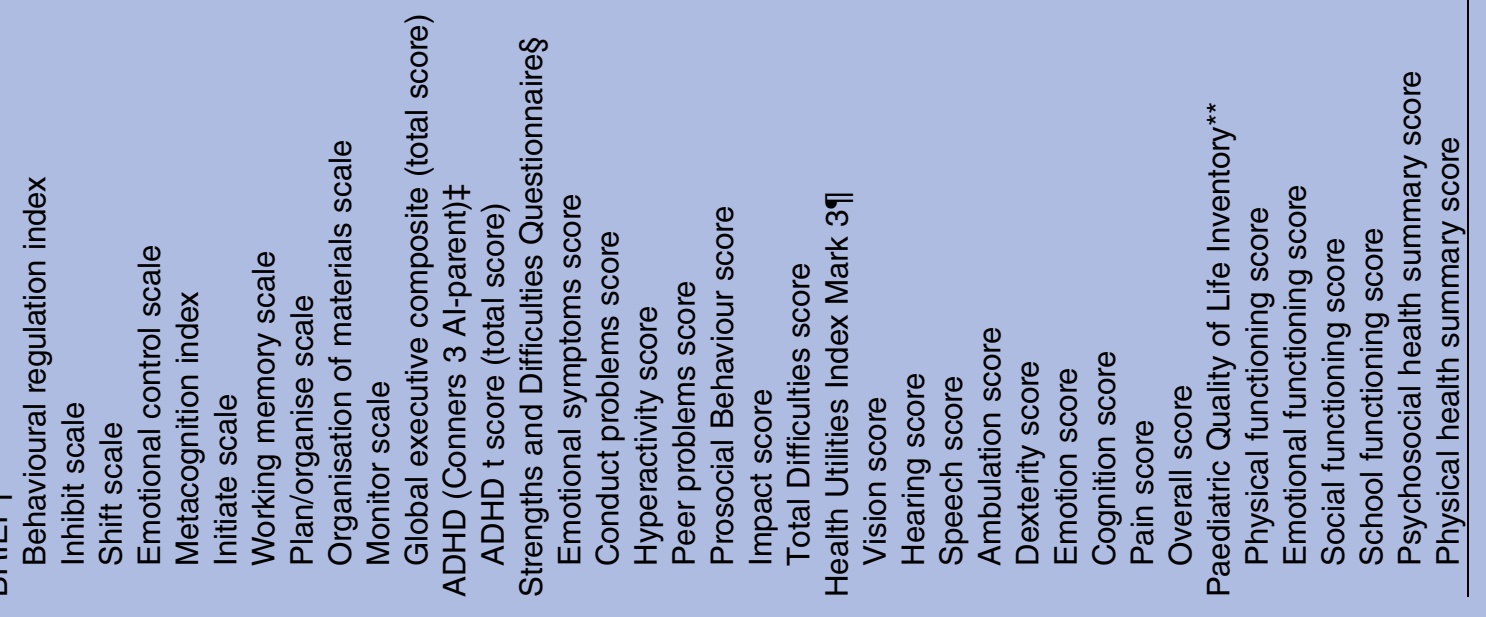




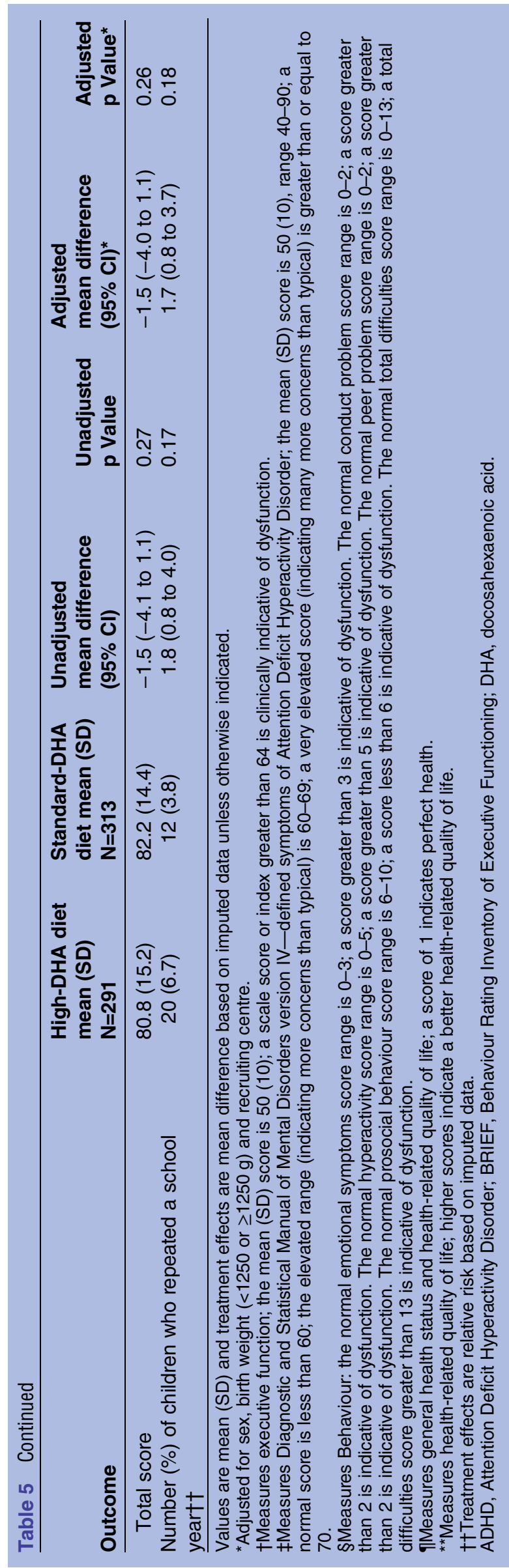

In secondary outcomes, there was a significant sex by treatment interaction effect in the Metacognition index $(\mathrm{p}=0.03)$ and Global Executive composite score $(\mathrm{p}=0.04)$ of the BRIEF parent report questionnaire. The Metacognition index assesses the ability to initiate, plan, organise, self-monitor and sustain working memory and the Global Executive composite is a summary score incorporating all the BRIEF clinical scales; scores $>64$ are indicative of a potential clinical problem. While both groups achieved scores in the normal range, girls in the high-DHA group scored significantly higher in both the Metacognition index and Global Executive composite compared with the standard-DHA group (see web appendix B).

There was no significant sex by treatment interaction effect for the total difficulties scale of the Strengths and Difficulties Questionnaire, or for any of the other scales except conduct problems $(\mathrm{p}=0.003)$. Both groups achieved a conduct problems score in the normal range (scores $>3$ are indicative of dysfunction), but girls in the high-DHA group scored significantly higher compared with girls in the standard-DHA group (see web appendix B). Subgroup analyses by sex for all primary and secondary outcomes are reported in web appendix $\mathrm{A}$ and $\mathrm{B}$.

\section{Subgroup analysis by randomisation strata-birth weight $<1250$ or $\geq 1250 \mathrm{~g}$}

There was no evidence of effect measure modification by birthweight strata for any outcome. Web appendices $\mathrm{C}$ and $\mathrm{D}$ show primary and secondary outcomes by birthweight strata.

\section{DISCUSSION}

\section{Principal findings}

Our data indicate that supplementing enteral feeds with DHA at $\approx 1 \%$ of total fatty acids from within the first week of life to 40 weeks' CA in children born at less than 33 weeks' gestation did not benefit IQ attention, executive function, behaviour, visual-spatial perceptual skills, educational progress and quality of life at 7 years' CA compared with a standard-DHA diet $(\approx 0.35 \%$ total fatty acids).

In prespecified subgroup analyses, parent-reported assessments indicated that girls in the high-DHA group had poorer executive function and more behavioural problems than girls in the standard-DHA group. The differences found may be due to chance, particularly given the high number of statistical comparisons, or may indicate a true underlying adverse effect of supplementation. Women in the high-DHA group were more likely to correctly guess their group allocation, ${ }^{6}$ so it is also possible that they had higher expectations of their children compared with women in the standard-DHA group. It is important to note that these results are inconsistent with those from direct assessment of executive function (the Rey Complex Figure and Fruit Stroop Test), which did not demonstrate differences between groups. There was no effect of birth weight $(<1250$ or $\geq 1250 \mathrm{~g})$ on any outcome. 


\section{Strengths and limitations}

This 7-year follow-up of our randomised controlled trial of preterm born children is the only study to evaluate the effect a diet that provides the estimated in utero accretion rate of DHA in infancy has on neurodevelopmental outcomes in the early school years. The strengths of the study include the sample size which was large enough to detect a four-point difference in Full Scale IQ if it existed, the low risk of bias achieved through blinding of research personnel, outcome assessors and participants (apart from the 12 families that requested to be unblinded), and the minimal rate of attrition. The follow-up had clinically relevant prespecified primary and secondary outcomes and a prespecified analysis plan. Robust objective assessments of neurodevelopmental outcomes were undertaken by psychologists after extensive training and ongoing auditing. Our study was a pragmatic trial involving five Australian perinatal centres suggesting generalisability of the results to the wider preterm infant population in developed countries. However, the study relied on the infant achieving full enteral feeds to receive the full dose of DHA delivered either through human milk or infant formula. DHA is well absorbed by preterm infants ${ }^{15}$ and this was reflected in the increase in the erythrocyte membrane phospholipid DHA status of infants in the treatment group. ${ }^{16}$ The erythrocyte DHA status achieved in the high-DHA group was greater than previous trials that used lower DHA doses, ${ }^{17}$ although it did not quite reach our target level. ${ }^{18}$ This may be due to the variation of DHA in breast milk, maternal compliance and delays in achieving the full DHA dose from intolerance to enteral feeds.

A limitation of the study was not including a teacher assessment of the child's behaviour as the diagnostic accuracy of both the Strengths and Difficulties Questionnaire and the BRIEF is superior when both parent and teacher reports are used. ${ }^{19} 20$

\section{Comparison with other studies}

Early DHA intervention trials in preterm infants compared infants that received formula supplemented with DHA with infants receiving formulas devoid of DHA. Benefits seen in the supplemented infants led to all preterm infant formula being supplemented with DHA at a dose comparable to the standard dose in our trial. There are only two trials of current clinical relevance, the DINO trial ${ }^{6}$ and that of Henriksen $e t a l^{5}{ }^{21}$ In both these trials, DHA doses reflective of the estimated in utero accretion rate and inclusive of breast milk feeding were used. ${ }^{5}{ }^{6}{ }^{21}$ We reported previously that providing enteral feeds containing DHA at $\approx 1 \%$ total fatty acids improved visual acuity at 4 months' $\mathrm{CA}^{7}{ }^{7}$ reduced cognitive delay, improved the neurodevelopment of girls and was strongly suggestive of improved neurodevelopment in infants born weighing $<1250 \mathrm{~g}$ at 18 months' CA compared with a standard-DHA diet. ${ }^{6}$ The DINO results were consistent with the only other preterm infant trial of high-DHA compared with standard-DHA where improvement in problem solving was demonstrated at 6 months' $\mathrm{CA}^{5}$ and in sustained attention at 20 months of age. ${ }^{21}$ However, their results need to be interpreted with caution due to the small sample size and large attrition. $^{21}$

Of the earlier studies comparing DHA supplemented formula with formula containing no DHA, only one trial has assessed children beyond 18 months of age to determine cognitive effects of DHA supplementation in infancy. ${ }^{22}$ In that study, preterm infants were randomised to receive formula supplemented with DHA (0.5\%) versus no DHA supplementation to 9 months postterm. ${ }^{23}$ As with our study, they found no significant differences between groups in Full Scale IQ or any cognitive outcome measures at 10 years of age. ${ }^{22}$ In contrast to our study, girls who received the DHA supplemented formula showed greater reading and spelling skills than girls in the control group. ${ }^{22}$ Their results, however, need to be interpreted with caution because of the high risk of bias due to incomplete outcome data with $55 \%$ attrition at the 10-year follow-up.

In a follow-up of a subset of this DINO cohort at 35 years' CA, no differences in parent-reported behaviour were detected but the results were limited by the sample size $(n=125) .{ }^{24}$ However, the parental report of poorer executive function and conduct problems in girls who received a high-DHA diet is consistent with results found in the DHA to Optimize Mother Infant Outcome trial. ${ }^{25}$ In that trial, women were supplemented with DHA during pregnancy and children were assessed at 4 years of age. Poorer scores on some but not all indices of parent-reported executive function and behaviour were found, although there was no evidence of effect modification by sex. ${ }^{25}$ Executive function has not been assessed during childhood in preterm infant DHA supplementation studies. Given the possibility of poorer executive function and conduct problems we found in girls who received a high-DHA diet, it will be important to determine if there is evidence of a difference in later childhood or adolescence. It is possible that the potential differences found may reduce with age. ${ }^{26}$

Biological and environmental factors interplay to influence cognitive development. In the long term, the effect of the family and environment may have a greater influence on cognitive outcomes. ${ }^{27-29}$ The most frequent indicator used for the family and environmental effect on cognitive outcomes in preterm infants has been maternal education level. ${ }^{27}$ While a composite measure of socioeconomic status may provide a more discriminant indicator, maternal education has consistently been shown to be associated with cognitive achievement. $^{27}$ There were no differences in maternal education level attained between the high-DHA and standard-DHA groups in our 7-year follow-up and the education level was similar to the Australian average. Therefore, at least on this somewhat limited indicator of socioeconomic status, both groups had the same socioeconomic influences. A weakening of differences in 
cognitive outcome between 18 months and early childhood was also seen in the 'Caffeine for Apnoea of Prematurity' trial where a cognitive benefit was found at 18 months, but by 5 years of age there was no difference. ${ }^{30}$ Thus, the early benefits of specific neonatal interventions appear to wane in middle childhood, but this does not discount delayed effects.

\section{Conclusions and policy implications}

There is limited evidence that DHA supplementation given in the first months of life to preterm infants benefits school-aged outcomes. Our results indicate that provision of enteral feeds containing a DHA dose of $\approx 1 \%$ of total fatty acids in the newborn period provides little evidence of long-term benefit.

\section{Author affiliations}

${ }^{1}$ Women's and Children's Health Research Institute, North Adelaide, South Australia, Australia

${ }^{2}$ Healthy Mothers, Babies and Children, South Australian Health and Medical Research Institute, Adelaide, South Australia, Australia

${ }^{3}$ School of Paediatrics and Reproductive Health, The University of Adelaide, Adelaide, South Australia, Australia

${ }^{4}$ F00Dplus Research Centre, The University of Adelaide, Adelaide, South Australia, Australia

${ }^{5}$ Clinical Sciences, The Murdoch Children's Research Institute, Parkville, Victoria, Australia

${ }^{6}$ Department of Paediatrics, The University of Melbourne, Royal Children's Hospital, Parkville, Victoria, Australia

${ }^{7}$ Department of Neonatal Medicine, Women's and Children's Hospital, North Adelaide, South Australia, Australia

${ }^{8}$ School of Population Health, The University of Adelaide, Adelaide, South Australia, Australia

${ }^{9}$ Department of Obstetrics and Gynaecology, The Royal Women's Hospital, Parkville, Victoria, Australia

${ }^{10}$ Centre of Neonatal Research and Education, The University of Western Australia, Perth, Western Australia, Australia

${ }^{11}$ King Edward Memorial Hospital and Princess Margaret Hospital for Children, Subiaco, Western Australia, Australia

${ }^{12}$ Perinatal Research Centre, University of Queensland Centre for Clinical Research, The University of Queensland, Royal Brisbane and Women's Hospital, Brisbane, Queensland, Australia

${ }^{13}$ Centre for Perinatal Medicine, Flinders Medical Centre and School of Medicine, Flinders University, Adelaide, South Australia, Australia

Acknowledgements The authors thank the families who generously participated in this study. Steering committee-CTC, MM, RAG, AJM, PR, TRS, PJA, LWD, PGD, PBC, NPF, JEM, A O'Grady (study coordinator, Women's and Children's Health Research Institute, Adelaide). Coordinating centre-staff at the Women's and Children's Health Research Institute, Adelaide, Australia. Data management-staff at the Data Management \& Analysis Centre, School of Population Health, The University of Adelaide, Adelaide, Australia. Mortality committee-J Lipsett and D Baulderstone, Women's and Children's Hospital, Adelaide, Australia. DINO Trial collaborating centres-the following investigators and research staff contributed to the 7-year follow-up of DINO trial participants. Study sites are listed in order of the number of children they enrolled. Women's and Children's Hospital, Adelaide, South Australia: AJM. King Edward Memorial Hospital, Perth, Western Australia: JEM, NPF, KS, C Kok, L Peake, C Campbell and the PROJECT K.I.D.S team. Royal Women's Hospital, Victoria: LWD, PJA, PGD, C Callanan, M McDonald, C Molloy, S Stokes. Royal Brisbane and Women's Hospital and the Perinatal Research Centre, University of Queensland Centre for Clinical Research, Queensland: PBC. Flinders Medical Centre, South Australia: SAM. This is an IMPACT (Interdisciplinary Maternal and Perinatal Australasian Clinical Trials) Network endorsed study.
Contributors CTC, RAG, PJA, AJM, TRS, PR, LWD, PGD, PBC, KS, SAM and $\mathrm{MM}$ were involved in the development and design of the trial. All authors were involved in the conduct of the trial. CTC drafted the manuscript. All authors critically revised and edited the manuscript and approved the final submitted version. TRS carried out the statistical analyses. All other authors had full access to all of the data in the study and take responsibility for the integrity of the data and the accuracy of the data analysis. CTC and MM are the guarantors of this study.

Funding This work was supported by a 5 -year project grant from the National Health and Medical Research Council (NHMRC), Australia (ID 508003) and Mead Johnson Nutrition. CTC is supported through a MS McLeod Postdoctoral Research Fellowship (MS McLeod Research Fund, Women's and Children's Hospital Research Foundation); NHMRC Fellowships support RAG (Senior Principal Research Fellow APP1046207), PJA (Senior Research Fellow APP628371), PGD (Practitioner Fellow APP1059111), PBC (Practitioner Fellow APP511117), MM (Principal Research Fellow APP1061704).

Competing interests All authors have completed the ICMJE uniform disclosure at ww.icmje.org/coi_disclosure.pdf and declare: financial support for the submitted work from the National Health and Medical Research Council (NHMRC) Australia for the original trial (ID 250322) and 7-year follow-up study (ID 508003) and from Mead Johnson Nutrition for the 7-year follow-up study. Treatment and placebo capsules for the original trial were donated by Clover Corporation and infant formula was donated by Mead Johnson Nutrition and Nutricia Australasia. CTC, RAG and MM have received non-financial support from Clover Corporation and Nestle Nutrition for research outside that of the submitted work. RAG serves on a scientific advisory board for Fonterra; MM serves on scientific advisory boards for Nestle, Fonterra and Nutricia. Associated honoraria for RAG and MM are paid to their respective institutions to support conference travel and continuing education for postgraduate students and early career researchers. MM and RAG, through the Women's and Children's Health Research Institute, have a patent pending "Methods and compositions for promoting the neurological development of an infant." KS received honoraria from the Nestle Nutrition Institute and grants from Medela Switzerland.

Ethics approval This study was approved by each collaborating centre: Flinders Medical Centre-Southern Adelaide Clinical Human Research Ethics Committee (Application 221.11); King Edward Memorial Hospital-Women and Newborn Health Service Ethics Committee (Registration Number 1832/ EW); The Royal Brisbane and Women's Hospital-Queensland Children's Health Services (RCH) Human Research Ethics Committee (Reference number $\mathrm{HREC} / \mathrm{ll} / \mathrm{QRCH} / 7$ ) and The University of Queensland Medical Research Ethics Committee (Project number 2012000021); The Royal Women's HospitalRoyal Women's Hospital Human Research Ethics Committee (Project 11/05); The Women's and Children's Hospital-Children Youth and Women's Health Service Research Ethics Committee (REC2015/11/10).

Provenance and peer review Not commissioned; externally peer reviewed.

Data sharing statement No additional data are available.

Open Access This is an Open Access article distributed in accordance with the Creative Commons Attribution Non Commercial (CC BY-NC 4.0) license, which permits others to distribute, remix, adapt, build upon this work noncommercially, and license their derivative works on different terms, provided the original work is properly cited and the use is non-commercial. See: http:// creativecommons.org/licenses/by-nc/4.0/

\section{REFERENCES}

1. Kerr-Wilson CO, Mackay DF, Smith GC, et al. Meta-analysis of the association between preterm delivery and intelligence. $J$ Public Health (Oxford) 2012;34:209-16.

2. Innis SM. Dietary (n-3) fatty acids and brain development. $J$ Nutr 2007;137:855-9.

3. Martinez M. Tissue levels of polyunsaturated fatty acids during early human development. J Pediatr 1992;120:S129-38.

4. Lapillonne A, Groh-Wargo S, Gonzalez CH, et al. Lipid needs of preterm infants: updated recommendations. J Pediatr 2013;162: S37-47.

5. Henriksen $\mathrm{C}$, Haugholt $\mathrm{K}$, Lindgren $\mathrm{M}$, et al. Improved cognitive development among preterm infants attributable to early 
supplementation of human milk with docosahexaenoic acid and arachidonic acid. Pediatrics 2008;121:1137-45.

6. Makrides M, Gibson RA, McPhee AJ, et al. Neurodevelopmental outcomes of preterm infants fed high-dose docosahexaenoic acid: a randomized controlled trial. JAMA 2009;301:175-82.

7. Smithers LG, Gibson RA, McPhee A, et al. Higher dose of docosahexaenoic acid in the neonatal period improves visual acuity of preterm infants: results of a randomized controlled trial. Am J Clin Nutr 2008;88:1049-56.

8. Hack M, Taylor HG, Drotar D, et al. Poor predictive validity of the bayley scales of infant development for cognitive function of extremely low birth weight children at school age. Pediatrics 2005;116:333-41.

9. Roberts G, Anderson PJ, Doyle LW; Group tVICS. The stability of the diagnosis of developmental disability between ages 2 and 8 in a geographic cohort of very preterm children born in 1997. Arch Dis Child 2010;95:786-90.

10. Wilson-Ching M, Pascoe L, Doyle LW, et al. Effects of correcting for prematurity on cognitive test scores in childhood. $J$ Paediatr Child Health 2014;50:182-8.

11. Manly $\mathrm{T}$, Robertson IH, Anderson V, et al. TEA-Ch: The test of everyday attention for children. Bury St Edmunds, England: Thames Valley Test Company Ltd, 1999.

12. Wilson-Ching M, Molloy CS, Anderson VA, et al. Attention difficulties in a contemporary geographic cohort of adolescents born extremely preterm/extremely low birth weight. JINS 2013;19:1097-108.

13. van Buuren $\mathrm{S}$. Multiple imputation of discrete and continuous data by fully conditional specification. Stat Methods Med Res 2007:16:219-42.

14. Rubin DB. Multiple imputation for nonresponse in surveys. New York: John Wiley \& Sons, 1987.

15. Carnielli VP, Simonato M, Verlato G, et al. Synthesis of long-chain polyunsaturated fatty acids in preterm newborns fed formula with long-chain polyunsaturated fatty acids. Am J Clin Nutr 2007;86:1323-30.

16. Smithers LG, Gibson RA, McPhee A, et al. Effect of two doses of docosahexaenoic acid (DHA) in the diet of preterm infants on infant fatty acid status: results from the DINO trial. Prostaglandins Leukot Essent Fatty Acids 2008;79:141-6.

17. Clandinin MT, Van Aerde JE, Parrott A, et al. Assessment of the efficacious dose of arachidonic and docosahexaenoic acids in preterm infant formulas: fatty acid composition of erythrocyte membrane lipids. Pediatr Res 1997;42:819-25.

18. Makrides M. DHA supplementation during the perinatal period and neurodevelopment: Do some babies benefit more than others? Prostaglandins Leukot Essent Fatty Acids 2013;88:87-90.
19. Johnson S, Hollis C, Marlow N, et al. Screening for childhood mental health disorders using the Strengths and Difficulties Questionnaire: the validity of multi-informant reports. Dev Med Child Neurol 2014:56:453-9.

20. Sullivan JR, Riccio CA. Diagnostic group differences in parent and teacher ratings on the BRIEF and Conners' Scales. J Atten Disord 2007:11:398-406

21. Westerberg AC, Schei R, Henriksen C, et al. Attention among very low birth weight infants following early supplementation with docosahexaenoic and arachidonic acid. Acta Paediatr 2011;100:47-52.

22. Isaacs $\mathrm{EB}$, Ross $\mathrm{S}$, Kennedy $\mathrm{K}$, et al. 10-year cognition in preterms after random assignment to fatty acid supplementation in infancy. Pediatrics 2011;128:e890-8.

23. Fewtrell MS, Abbott RA, Kennedy K, et al. Randomized double-blind trial of long-chain polyunsaturated fatty acid supplementation with fish oil and borage oil in preterm infants. J Pediatr 2004;144:471-9.

24. Smithers LG, Collins CT, Simmonds LA, et al. Feeding preterm infants milk with a higher dose of docosahexaenoic acid than that used in current practice does not influence language or behavior in early childhood: a follow-up study of a randomized controlled trial. Am J Clin Nutr 2010;91:628-34.

25. Makrides M, Gould JF, Gawlik NR, et al. Four-year follow-up of children born to women in a randomized trial of prenatal DHA supplementation. JAMA 2014;311:1802-4.

26. Mulder H, Pitchford NJ, Hagger MS, et al. Development of executive function and attention in preterm children: a systematic review. Dev Neuropsychol 2009;34:393-421.

27. Wong HS, Edwards P. Nature or nurture: a systematic review of the effect of socio-economic status on the developmental and cognitive outcomes of children born preterm. Matern Child Health $J$ 2013;17:1689-700.

28. Schneider LA, Burns NR, Giles LC, et al. Cognitive abilities in preterm and term-born adolescents. J Pediatr 2014;165:170-7.

29. Fawer CL, Besnier S, Forcada M, et al. Influence of perinatal, developmental and environmental factors on cognitive abilities of preterm children without major impairments at 5 years. Early Hum Dev 1995;43:151-64.

30. Schmidt B, Anderson PJ, Doyle LW, et al. Survival without disability to age 5 years after neonatal caffeine therapy for apnea of prematurity. JAMA 2012;307:275-82.

31. Cole TJ, Freeman JV, Preece MA. British 1990 growth reference centiles for weight, height, body mass index and head circumference fitted by maximum penalized likelihood. Stat Med 1998;17:407-29. 